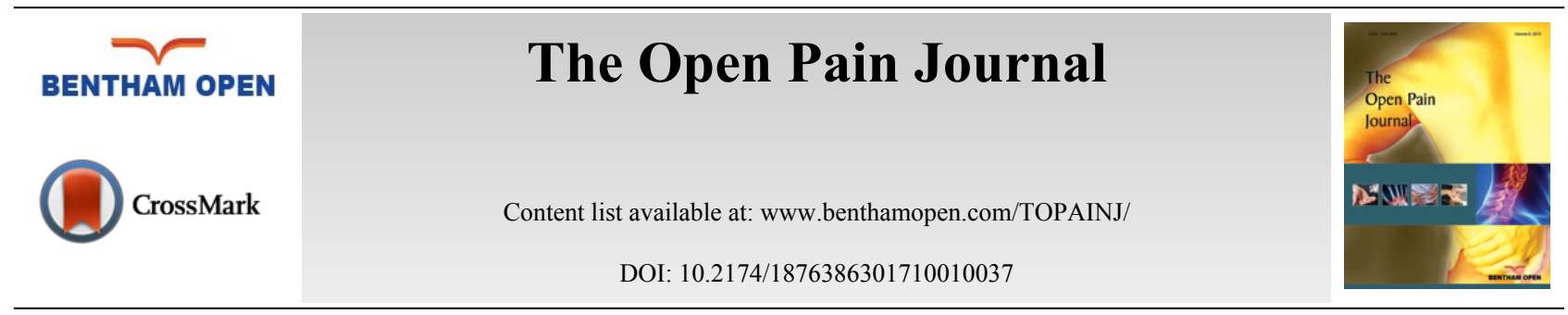

RESEARCH ARTICLE

\title{
Rat Running Wheel Behavior Reflects Inflammatory, Orofacial Pain
}

\author{
Patrick Farrow and Kevin Rowland* \\ School of Dental Medicine, Southern Illinois University, Alton, IL 62002, USA
}

Received: January 26, 2017

Revised: May 17, 2017

Accepted: June 01, 2017

\begin{abstract}
:
Background:

Our objective was to establish a novel, unbiased metric of inflammatory, orofacial pain.
\end{abstract}

\section{Method:}

Rats were placed individually into cages equipped with running wheels, and allowed an acclimation period of 17 days. Diurnal and nocturnal voluntary running behaviors were recorded. After day 17, rats were deeply anesthetized and divided into mustard oil, vehicle (mineral oil) and drug (ibuprofen) groups. Injections of mustard oil or mineral oil were made into the vestibule superior to the maxillary molar. Running wheel behavior was recorded for three days following the procedure.

\section{Results:}

After acclimation, the average percentage of running behavior that occurred at night was $94 \%+/-1 \%$ SE. Mustard oil injections caused externally observable, unilateral inflammation. On average, mustard oil injections significantly reduced nocturnal running on the first and second nocturnal periods post-injection. The non-steroidal anti-inflammatory, ibuprofen, significantly improved running behavior during the second nocturnal period, which was abolished when removed during the third nocturnal period.

\section{Conclusions:}

We conclude that unilateral injections of algogens in the vestibule coupled with analysis of nocturnal running behavior is an effective method to measure acute inflammatory pain for three days that mirrors many painful clinical situations. The model could be used as inexpensive, quantitative method to evaluate putative pain relieving therapeutics.

Keywords: Behavior, Mustard oil, Orofacial pain, Rat, Running, Spontaneous pain.

\section{INTRODUCTION}

The United States is currently facing an epidemic of prescription painkiller abuse. Addictions and overdoses to prescription opioids are steadily on the rise, as highlighted by a recent report from the CDC indicating that overdose deaths from prescription opioids exceed deaths from cocaine and heroin combined. Moreover, the United States spends approximately, $\$ 500$ billion annually in costs associated with treating painful conditions [1]. In addition to the financial toll, patients dealing with chronic pain also have a significantly reduced quality of life. Hence, there is a growing impetus and need for novel, non-addicting therapies to treat pain. However, there are many barriers to developing new therapies, which include appropriate pre-clinical animal testing. There has been considerable debate on the most appropriate pre-clinical animal model used to approximate human conditions. Many pre-clinical animal models utilize pain-stimulating (evoked) behaviors [2 - 5], where a variety of measures such as withdrawal latencies, threshold, and number of evoked responses are measured. Evoked pain models have been criticized over spontaneous pain models, which have been argued to more accurately reflects human pain symptoms [6]. However, differentiating between evoked pain and spontaneous pain is not straightforward [7] and it has been suggested that ongoing inflammatory pain should not be characterized as spontaneous pain [7]. Animal testing often utilizes techniques that subject animals to a

\footnotetext{
* Address correspondence to this author at the Southern Illinois University, School of Dental Medicine, Alton, IL 62002, USA; Tel: 618-474-7212;
} E-mail: krowlan@siue.edu 
battery of tests, often require extensive investigator/animal training and rarely evaluates motivation and choice which is more reflective of the human condition.

Our approach takes advantage of a rat's natural, nocturnal running inclination [8] as a measure of orofacial pain and inflammation. The objective of our study was to assess the role of orofacial nociception and inflammation on voluntary running behavior in rats. We compared rats that had received chemical injection of the known noxious stimulant mustard oil, into the orofacial cavity to their own baseline activity and to rats that received an analgesic. Mustard oil injections are effective at producing robust pain and inflammation $[9,10]$ by activating sensory nerve fibers through TRPA1 channels [11]. Our model relates orofacial pain with voluntary running behavior and is without experimenter bias in method or interpretation.

\section{MATERIALS AND METHODS}

A total of 16 male, Sprague-Dawley rats (Harlan Laboratories, Indianapolis, IN) weighing approximately 150 grams were obtained and divided randomly into three groups 1) experimental, 2) drug, 3) vehicle. Rats were housed individually into cages equipped with $36 \mathrm{~cm}$ diameter running wheels and a counter (Harvard Apparatus, Holliston, MA). The counter recorded the number of revolutions, but did not record the rate or time the activity occurred. The running wheel can rotate in either direction. Animals were housed in a room on a 12-hour light/dark cycle and rats had free access to the wheel, food and water. Numbers of revolutions were recorded for each rat for each diurnal/nocturnal period.

In the first set of experiments, animal running behaviors plateaued after 17 days (Fig. 1) and we decided to begin the experimental phase. The plateau observed is consistent with another study reporting stabilization at days 17-21 [12]. Rats were deeply anesthetized with 5\% isoflurane (Henry Schein, Mellville, NY) in an induction chamber, maintained with 3\% isoflurane via a nosecone throughout the procedure. Their mouths were gently held open with an alm retractor and injections of $100 \mathrm{uL}$ of either $10 \%$ mustard oil (allyl isothiocyanate, Sigma Aldrich, St. Louis, MO; dissolved in mineral oil; $n=5$ ) or $100 \%$ mineral oil (vehicle; Walgreen Co., Deerfield, IL; $n=2$ ) were made with a 26 gauge needle into the upper left maxillary buccal vestibule. Injections were made during the first hour of the diurnal period to allow for the maximum interval of time between the administration of anesthesia and the beginning of the nocturnal recording session. Rats were immediately returned to their originally assigned cages. Some animals, intermixed with the others, were acclimated and received mustard oil injections as above, but received water with dissolved ibuprofen $0.3 \mathrm{mg} / \mathrm{ml}$ at the start of the second nocturnal period $(\mathrm{n}=9)$. We elected to use the dosing of $.3 \mathrm{mg} / \mathrm{ml}$ for ibuprofen, which is based upon the average water intakes amounts to approximately $10 \mathrm{mg}$ during the nocturnal period and mirror other studies related to nociceptive stimuli and healing in rats [13].

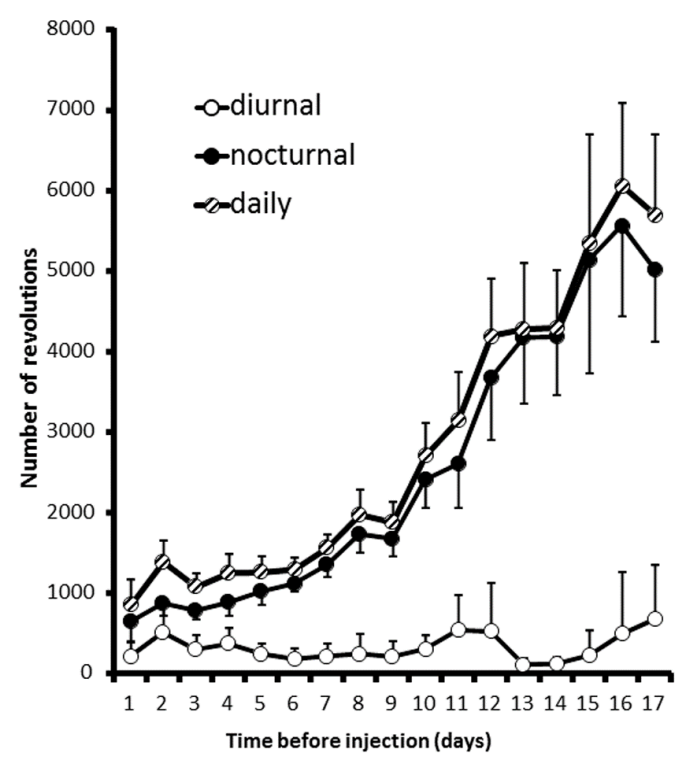

Fig. (1). Average number of revolutions traveled over 17 days during the diurnal, nocturnal and 24-hour periods of voluntary running rats $(n=16)$. 


\subsection{Analysis}

Since greater than $95 \%$ of the running activity occurred during the nocturnal period, data are presented as average percent differences from baseline nocturnal activity. Wheel activity was normalized by dividing each rat's post-injection values by the average of its own last two nocturnal periods of activity during the acclimation period. Data are represented as means +/- SE. Differences between groups were determined by a one-way analysis of variance with significance set at 0.05 .

\section{RESULTS}

\subsection{Baseline Activity}

Running wheel activity was greatest during the nocturnal period (Fig. 1). During the last day of the acclimation period, nocturnal activity of all rats averaged $5.4+/-1.0 \mathrm{~km} /$ night (range: $1.2-11.3 \mathrm{~km} / \mathrm{night}$ ). The average baseline nocturnal running behavior in each of our three groups, mustard oil, mineral oil, and drug, were 5.2 +/- 1.7, 5.3 +/- 2.1, and $5.6+/-1.3 \mathrm{~km} /$ night, respectively, and did not differ significantly between groups $(p=0.98$; ANOVA single factor between groups comparison). Because of the wide range of individual running behaviors for each rat, each rat was compared to its own baseline activity and that activity was averaged within the group.

\subsection{Mustard Oil Injections (Experimental)}

Unilateral mustard oil injections into the vestibule caused observable buccal swelling, with eye involvement, within approximately ten minutes, which persisted for approximately four days $(n=5$; Fig. 2). Average running behavior differences from baseline during the first and second nocturnal periods were $-84.8+/-9.3$ and $-55.6+/-13.6 \%$, respectively, and were significantly lower than baseline values $(\mathrm{p}<0.0001$ and $p<0.003$, respectively; Fig. 3). Reductions in running behaviors of mustard oil injected rats were significantly different on the first nocturnal period compared to vehicle-injected rats $(p<0.05$; post-hoc analysis yielded a Power $>95 \%)$. On the third nocturnal period following mustard oil injection, running behavior differences from baseline were, on average, $-30.8+/-17.4 \%$, but did not significantly differ from baseline running levels ( $p=0.11$; Fig. 3 ).

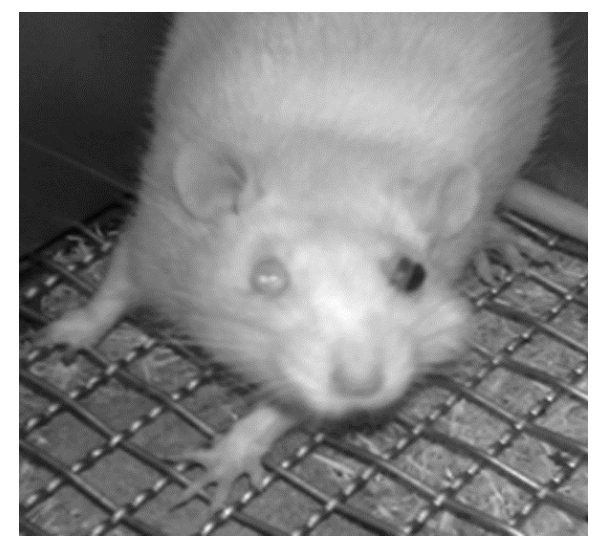

Fig. (2). Exemplar rat following 10\% mustard oil injection into the vestibule above the second molar. Note the significant, left buccal swelling and eye discoloration.

\subsection{Mustard Oil Injections + Night Two Ibuprofen (Drug)}

To validate that the statistically significant decrease in running behavior versus baseline was due to increased nociceptive activity, $0.3 \mathrm{mg} / \mathrm{ml}$ ibuprofen was added to the water at the beginning of the second nocturnal period. As expected, on the first nocturnal period, average rat running behavior differences from baseline following mustard oil injection significantly decreased $(-73.5+/-7.5 \% ; p<0.0001)$. Rats that had access with water containing ibuprofen restored their running activity toward baseline activity $(-21.9+/-8.4 \%)$ and the recovery was significantly better than the mustard oil alone group ( $p<0.05$; Fig. 3). After the removal of ibuprofen during the third nocturnal period, running activity on average declined, rather than improved, to $34.7+/-5.9 \%$. On an individual basis, 6 out of $9(66.6 \%)$ rats exhibited a decline in activity from the second to third nocturnal periods, whereas 0 out $5(0.0 \%)$ rats exhibited a decline after the second nocturnal period in the mustard oil alone group. 


\subsection{Mineral Oil Injections (Vehicle)}

Unilateral mineral oil injections into the vestibule did not cause observable changes in the face or the eyes of the animals $(n=2)$. Mineral oil injections significantly reduced running behavior versus baseline levels on the first nocturnal period $(-23.2+/-0.2 \% ; p<0.001)$, and was significantly different than the mustard oil injected animals $(p<0.05 ;$ posthoc, Power analysis $>95 \%)$ but animals returned to baseline activity levels on the second $(+6.7+/-27.1 \% ; p=0.8)$ and third nocturnal periods $(+0.5+/-16.9 \%, p=0.9$; Fig. 3).

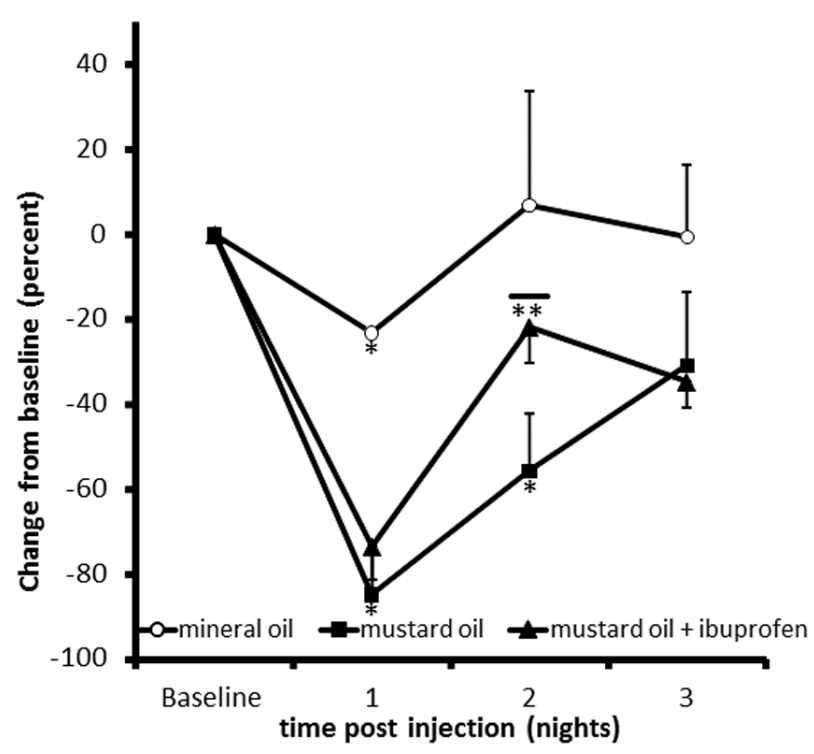

Fig. (3). Percent change from baseline in mineral oil and mustard oil injected rats. Ibuprofen provided ad libitum in drinking water on night two (bar) significantly attenuated the depression in running during the second nocturnal period. $* P<0.01$ versus baseline; $* * P<0.05$ versus experimental group.

\section{DISCUSSION}

We found that focal, unilateral mustard oil injections into the orofacial cavity caused significant decreases in nocturnal voluntary running behavior which persisted for approximately 48 hours. We also found that a high dose of the NSAID, ibuprofen, attenuated the decrease in running when administered during the second nocturnal period. Decreased voluntary running did not reach statistical significance on the third nocturnal period, which may be due to a low number of animals and diffusion of the mustard oil, but may be due to beneficial effects from exercise, including reduced hyperalgesia [14 - 16], and reduced "depression" [17].

To our knowledge, our study is the first to report on voluntary running behaviors in a rodent orofacial hociceptive model. Voluntary running behaviors are depressed in complete Freund's adjuvant (CFA) injected hindpaws [18, 19], and are likely the result of evoked pain [7]. Running activity in our model most likely causes evoked pain from movement of the inflamed cheek directly stimulating nociceptors, but we argue that the pain felt is less than models that inject algesic chemicals into the hindpaw or osteoarthritic models [12], where the paw and limbs are directly stimulated by running. In our study, rats injected with mineral oil also displayed a modest reduction in voluntary running compared to baseline on the first nocturnal period $(<25 \%)$, but recovered on the second and third nocturnal period. The decrease in running of rats injected with mineral oil may have resulted from lingering effects of the anesthesia, stress or pain from the injection. The equipment used in our study does not have the ability to determine the number of attempts that the animal made at running, which may reveal whether the decrease is from evoked-pain or reduced motivation.

Our finding that mustard oil injections causes acute, swelling is not novel, as mustard oil has long been used as a chemical irritant to induce orofacial pain [20 - 22] and is known to cause central sensitization when applied directly to the tooth pulp [23]. The concentration of mustard oil used in the present study was used as a starting point and is within the range of published studies that established mustard oil as an inflammatory irritant in the temporomandibular joint $[20,21]$. However, we used a higher volume $(100 \mathrm{uL})$, as we questioned whether the solution would dissipate in the relatively larger space. Animals injected with mustard oil in the present study had eye involvement that persisted for 
approximately three days. Rats displayed some aspects of "red tears", caused by the secretion of the pigment porphyrin, a condition known as chromodacryorrhea which has been used as a metric in a model of temporomandibular joint inflammation/pain [24]. Although running activity was recorded during the nocturnal period, without any light in the facility, loss of vision and decreased eye coordination may have contributed to the decreased voluntary running observed. Ibuprofen attenuated the decrease in running behavior on the second nocturnal period, and we argue that the animal benefitted from both the analgesic and anti-inflammatory properties of the drug. We choose ibuprofen, rather than opioids, to decrease the effect of loss of ambulatory ability associated with narcotics [25]. Future study using our model could evaluate the dose dependency of ibuprofen and mustard oil, the effects of ibuprofen alone and the efficacy of other known analgesics on running behavior. Another limitation of our study includes the use of only male rats. Indeed, important differences exist in nociception between the sexes exist, including in the orofacial complex [26], and comparative studies using our model are warranted.

Several different models to study orofacial pain currently exist which have recently been reviewed [27]. Orofacial pain models include orofacial formalin or CFA tests where behavioral measures of pain, such as face-rubbing [28 - 30], are defined and quantified or operant models where reward systems are utilized [31]. Another interesting study utilized a metric of chewing, through a plastic dowel, as a measure of pain [32]. Additionally, mice display empathetic behaviors when injected with acid, and will display heightened pain behaviors when mice in pain are nearby, even when housed separately [33]. In the present study, rats were housed singly but might have observed nociceptive pain behaviors via visual, auditory or olfactory cues and may have affected our results [33].

Our study has several advantages over existing current orofacial pain models in that, animals are observed for long periods of time rather than limited observations of behaviors, which are usually recorded when the animal would normally be sleeping. We have no experimenter bias, as there is no training of the investigator or animal. Stress on the animals is significantly lowered in our study because we have intentionally minimized interventions and the animal is housed in the same environment as the running wheel [34]. Another advantage is that voluntary running is fully by choice and may be more reflective of a quality of life indicator in humans. Admittedly, chemical induction of nociception into the perioral cavity does not exactly mimic any clinically painful condition in the human, in our model or others, but may have a close resemblance to the pain and inflammation experienced following a molar extraction, post-surgical or post-implant placement. Future study may include testing of new anti-inflammatory agents.

Decreases in food and water intake as a result of the facial edema observed in the present study may have adversely affected hydration and nutrition and therefore contributed to the observed decrease in voluntary running. However, as part of another study in our laboratory where animals received identical injections as the present study, water drinking behaviors for two days prior to injections did not significantly differ from post-injection values $(\mathrm{n}=6 ; 37.6+/-2.6 v s$. $35.2+/-2.3 \mathrm{~mL} ; \mathrm{p}=0.51)$. Future study should include monitoring of food intake and body weights. Other studies may include injection of algesic substances into the temporomandibular joint or masseter as clinical correlates of joint and masticatory inflammatory pain or a study to determine the effects of chronic orofacial pain, using a chronic constriction injury, on voluntary wheel running.

\section{CONCLUSION}

In the present study, introduction of a noxious stimulus into the orofacial cavity of rats caused significant, transient reductions in nocturnal free running behavior. We conclude that our model accurately reflects acute, orofacial nociception and could be used to test other nociceptive models and to test the efficacy of putative pain relieving drugs.

\section{ETHICS APPROVAL AND CONSENT TO PARTICIPATE}

Ethical approval was granted by the Institutional Animal Care and Use Committee of Southern Illinois University Edwardsville (\#022112).

\section{HUMAN AND ANIMAL RIGHTS}

No humans were used in this research. All animal research procedures followed were in accordance with the standards set forth in the eighth edition of Guide for the Care and Use of Laboratory Animals published by the National Academy of Sciences, The National Academies Press, Washington, D.C.).

\section{CONSENT FOR PUBLICATION}

Not applicable. 


\section{CONFLICT OF INTEREST}

The authors confirm that this article content has no conflict of interest.

\section{ACKNOWLEDGEMENTS}

The authors would like to thank Dr. Adriana Marcuzzi for expert technical assistance.

\section{REFERENCES}

[1] Academies IoMotN. Relieving pain in America. A Blueprint for Transforming Prevention, Care, Education, and Research 2011.

[2] Le Bars D, Gozariu M, Cadden SW. Animal models of nociception. Pharmacol Rev 2001; 53(4): $597-652$. [PMID: 11734620]

[3] Le Bars D, Gozariu M, Cadden SW. Critical analysis of animal models of acute pain. II. Ann Fr Anesth Reanim 2001; $20(5)$ : $452-70$. [http://dx.doi.org/10.1016/S0750-7658(01)00399-9] [PMID: 11419240]

[4] Le Bars D, Gozariu M, Cadden SW. Acute pain measurement in animals. Part 1. Ann Fr Anesth Reanim 2001; 20(4): $347-65$. [http://dx.doi.org/10.1016/S0750-7658(01)00381-1] [PMID: 11392245]

[5] Mogil JS. Animal models of pain: progress and challenges. Nat Rev Neurosci 2009; 10(4): 283-94. [http://dx.doi.org/10.1038/nrn2606] [PMID: 19259101]

[6] Backonja MM. Neuropathic pain therapy: from bench to bedside. Semin Neurol 2012; 32(3): 264-8. [http://dx.doi.org/10.1055/s-0032-1329204] [PMID: 23117951]

[7] Bennett GJ. What is spontaneous pain and who has it? J Pain 2012; 13(10): 921-9. [http://dx.doi.org/10.1016/j.jpain.2012.05.008] [PMID: 22824584]

[8] Verwey M, Robinson B, Amir S. Verwey M, Robinson B, Amir S. Recording and analysis of circadian rhythms in running-wheel activity in rodents. J Vis Exp 2013; (71).

[9] Everaerts W, Gees M, Alpizar YA, et al. The capsaicin receptor TRPV1 is a crucial mediator of the noxious effects of mustard oil. Curr Biol $2011 ; 21(4): 316-21$. [http://dx.doi.org/10.1016/j.cub.2011.01.031] [PMID: 21315593]

[10] DeBerry JJ, Schwartz ES, Davis BM. TRPA1 mediates bladder hyperalgesia in a mouse model of cystitis. Pain 2014; $155(7)$ : $1280-7$. [http://dx.doi.org/10.1016/j.pain.2014.03.023] [PMID: 24704367]

[11] Jordt SE, Bautista DM, Chuang HH, et al. Mustard oils and cannabinoids excite sensory nerve fibres through the TRP channel ANKTM1. Nature 2004; 427(6971): 260-5. [http://dx.doi.org/10.1038/nature02282] [PMID: 14712238]

[12] Stevenson GW, Mercer H, Cormier J, et al. Monosodium iodoacetate-induced osteoarthritis produces pain-depressed wheel running in rats: implications for preclinical behavioral assessment of chronic pain. Pharmacol Biochem Behav 2011; 98(1): 35-42. [http://dx.doi.org/10.1016/j.pbb.2010.12.009] [PMID: 21147151]

[13] Altman RD, Latta LL, Keer R, Renfree K, Hornicek FJ, Banovac K. Effect of nonsteroidal antiinflammatory drugs on fracture healing: a laboratory study in rats. J Orthop Trauma 1995; 9(5): 392-400. [http://dx.doi.org/10.1097/00005131-199505000-00006] [PMID: 8537842]

[14] Kuphal KE, Fibuch EE, Taylor BK. Extended swimming exercise reduces inflammatory and peripheral neuropathic pain in rodents. J Pain 2007; 8(12): 989-97.

[http://dx.doi.org/10.1016/j.jpain.2007.08.001] [PMID: 17890162]

[15] Sharma NK, Ryals JM, Gajewski BJ, Wright DE. Aerobic exercise alters analgesia and neurotrophin-3 synthesis in an animal model of chronic widespread pain. Phys Ther 2010; 90(5): 714-25. [http://dx.doi.org/10.2522/ptj.20090168] [PMID: 20338916]

[16] Stagg NJ, Mata HP, Ibrahim MM, et al. Regular exercise reverses sensory hypersensitivity in a rat neuropathic pain model: role of endogenous opioids. Anesthesiology 2011; 114(4): 940-8. [http://dx.doi.org/10.1097/ALN.0b013e318210f880] [PMID: 21386701]

[17] Bjørnebekk A, Mathé AA, Brené S. The antidepressant effect of running is associated with increased hippocampal cell proliferation. Int J Neuropsychopharmacol 2005; 8(3): 357-68.

[http://dx.doi.org/10.1017/S1461145705005122] [PMID: 15769301]

[18] Grace PM, Strand KA, Maier SF, Watkins LR. Suppression of voluntary wheel running in rats is dependent on the site of inflammation: evidence for voluntary running as a measure of hind paw-evoked pain. J Pain 2014; 15(2): 121-8. [http://dx.doi.org/10.1016/j.jpain.2013.10.001] [PMID: 24287315]

[19] Kandasamy R, Calsbeek JJ, Morgan MM. Home cage wheel running is an objective and clinically relevant method to assess inflammatory pain in male and female rats. J Neurosci Methods 2001; 263: 115-22.

[20] Haas DA, Nakanishi O, MacMillan RE, Jordan RC, Hu JW. Development of an orofacial model of acute inflammation in the rat. Arch Oral Biol 1992; 37(5): 417-22. 
[http://dx.doi.org/10.1016/0003-9969(92)90026-5] [PMID: 1610310]

[21] Yu XM, Sessle BJ, Vernon H, Hu JW. Effects of inflammatory irritant application to the rat temporomandibular joint on jaw and neck muscle activity. Pain 1995; 60(2): 143-9.

[http://dx.doi.org/10.1016/0304-3959(94)00104-M] [PMID: 7784099]

[22] Noguchi M, Kurose M, Yamamura K, et al. Unilateral application of an inflammatory irritant to the rat temporomandibular joint region produces bilateral modulation of the jaw-opening reflex. Brain Res Bull 2005; 67(3): 182-8. [http://dx.doi.org/10.1016/j.brainresbull.2005.06.013] [PMID: 16144653]

[23] Wang H, Xie YF, Chiang CY, Dostrovsky JO, Sessle BJ. Central $\alpha$-adrenoceptors contribute to mustard oil-induced central sensitization in the rat medullary dorsal horn. Neuroscience 2013; 236: 244-52. [http://dx.doi.org/10.1016/j.neuroscience.2013.01.016] [PMID: 23333675]

[24] Kerins CA, Carlson DS, Hinton RJ, et al. Specificity of meal pattern analysis as an animal model of determining temporomandibular joint inflammation/pain. Int J Oral Maxillofac Surg 2005; 34(4): 425-31. [http://dx.doi.org/10.1016/j.ijom.2004.08.010] [PMID: 16053854]

[25] Silva MT, Heyman GM. Chronic morphine consumption decreases wheel running and wheel running-reinforced behavior in rats. Pharmacol Biochem Behav 2001; 69(1-2): 51-7. [http://dx.doi.org/10.1016/S0091-3057(01)00498-1] [PMID: 11420068]

[26] Fischer L, Clemente JT, Tambeli CH. The protective role of testosterone in the development of temporomandibular joint pain. J Pain 2007; 8(5): 437-42. [http://dx.doi.org/10.1016/j.jpain.2006.12.007] [PMID: 17360240]

[27] Krzyzanowska A, Avendaño C. Behavioral testing in rodent models of orofacial neuropathic and inflammatory pain. Brain Behav 2012; 2(5): 678-97.

[http://dx.doi.org/10.1002/brb3.85] [PMID: 23139912]

[28] Quintans-Júnior LJ, Melo MS, De Sousa DP, et al. Antinociceptive effects of citronellal in formalin-, capsaicin-, and glutamate-induced orofacial nociception in rodents and its action on nerve excitability. J Orofac Pain 2010; 24(3): 305-12. [PMID: 20664833]

[29] Romero-Reyes M, Akerman S, Nguyen E, et al. Spontaneous behavioral responses in the orofacial region: a model of trigeminal pain in mouse. Headache 2013; 53(1): 137-51. [http://dx.doi.org/10.1111/j.1526-4610.2012.02226.x] [PMID: 22830495]

[30] Morgan JR, Gebhart GF. Characterization of a model of chronic orofacial hyperalgesia in the rat: contribution of NA(V) 1.8. J Pain 2008; 9(6): 522-31.

[http://dx.doi.org/10.1016/j.jpain.2008.01.326] [PMID: 18337185]

[31] Nolan TA, Hester J, Bokrand-Donatelli Y, et al. Adaptation of a novel operant orofacial testing system to characterize both mechanical and thermal pain. Behav Brain Res 217(2): 477-80. [http://dx.doi.org/10.1016/j.bbr.2010.10.022]

[32] Dolan JC, Lam DK, Achdjian SH, Schmidt BL. The dolognawmeter: a novel instrument and assay to quantify nociception in rodent models of orofacial pain. J Neurosci Methods 2010; 187(2): 207-15. [http://dx.doi.org/10.1016/j.jneumeth.2010.01.012] [PMID: 20096303]

[33] LangFord DJ, Crager SE, Shehzad Z, et al. Social modulation of pain as evidence for empathy in mice. Science 2006, 312(5728):1967-70.

[34] Balcombe JP, Barnard ND, Sandusky C. Laboratory routines cause animal stress. Contemp Top Lab Anim Sci 2004; 43(6): $42-51$. [PMID: 15669134]

(C) 2017 Farrow and Rowland.

This is an open access article distributed under the terms of the Creative Commons Attribution 4.0 International Public License (CC-BY 4.0), a copy of which is available at: (https://creativecommons.org/licenses/by/4.0/legalcode). This license permits unrestricted use, distribution, and reproduction in any medium, provided the original author and source are credited. 